\title{
Effect of Winter Temperature Increase on Prolonging Green Period of Lawn
}

\author{
Chunlei Ji, Huansheng Shi, Min Liu* and Xiaqing Chen \\ China Railway Fifth Survey And Design Institute Group co.,LTD, Beijing, Beijing 102600, China
}

\begin{abstract}
Taking mixed lawn of Festuca elata Keng ex E. Alexeev and Poa pratensis L. as the research object, through the comparison of the electric heating, covering by non-woven fabric or electric heating and non-woven fabric treatment group with the control group, exploring the effects of winter temperature increase on prolonging the green period of lawn. The results show that: compared with the control group, different temperature increasing measures have different effects on prolonging the green period of the lawn. The test group using only electric heating or only covering the non-woven fabric was completely yellow in mid-January, which was about 10 days longer than the green period of the control group. The effect of using electric heating and non-woven fabric was the best. During the research period, the lawn of this group did not appear completely yellow. Compared with the control group, the green period was prolonged by about 53 days.
\end{abstract}

\section{Introduction}

The lawn has important ecological functions such as purifying air and maintaining water and soil. It has a prominent role in slope protection of road traffic and landscape construction in service areas ${ }^{[1]}$, and has been valued and developed in fields such as garden landscapes and sports ${ }^{[2-3]}$. At present, the lawn industry has become a specialized industry in developed countries ${ }^{[4]}$. Compared with developed countries, China's lawn industry has a certain gap in terms of lawn scale, production, service projects, and related scientific research and education [5]. An important trend in the development of modern lawn industry is to pursue the ornamental effect of the four seasons, but it is not easy to achieve such effects in areas with hot summers and cold winters ${ }^{[6]}$. Therefore, the pursuit of four seasons evergreen through technical means to extend the green period of the lawn has important theoretical and practical significance for its ecological and social functions.

\section{Materials and methods}

\subsection{Overview of Experimental Field}

The experimental field is located in Tianjin Binhai District, $38^{\circ} 40^{\prime} \sim 39^{\circ} 00^{\prime} \mathrm{N}, 117^{\circ} 20^{\prime} \sim 118^{\circ} 00^{\prime} \mathrm{E}$ at an altitude of 3 meters. It belongs both the warm temperate monsoon continental and marine climate. The mean annual temperature is $13.0^{\circ} \mathrm{C}$, the extreme temperature is $40.9{ }^{\circ} \mathrm{C}$, the lowest temperature is $-18.3{ }^{\circ} \mathrm{C}$, and the mean annual frost-free period is $196 \sim 246$ days. The precipitation is $566.0 \mathrm{~mm}$, less in winter and spring, and concentrated in summer. There are many windy days throughout the year, with 57 gale days above level 8 . The test area is coastal saline-alkali land, the soil is alkaline with $8.5 \sim 8.7 \mathrm{pH}$ value. In order to eliminate its adverse effects on lawn growth, salt removal projects and soil improvement projects were implemented before laying the lawn.

\subsection{Experimental Material}

The experimental materials were Poa pratensis L., Conney and Festuca arundinace, Hound No.5, 2 cold-type turf grasses, which were planted in a ratio of 3 : 7. The total area is $192 \mathrm{~m}^{2}$.

\subsection{Experimental Treatment}

This experiment set three different treatment methods: (1) Heating by electric heating wire $(\mathrm{H}), 2000 \mathrm{w}$ nickel-chromium heating wire is buried in the planting soil, with $25 \mathrm{~cm}$ depth and $20 \mathrm{~cm}$ gap. (2) Covering by non-woven fabric (C), covering the lawn with $100 \mathrm{~g} / \mathrm{m}^{2}$ non-woven fabric, and fixing it with bricks every $50 \mathrm{~cm}$ and uncovering when the temperature above $5^{\circ} \mathrm{C}$; (3) Combined processing $(\mathrm{H}+\mathrm{C})$, the non-woven fabric is covered on the lawn with electric heating wires, and the method of opening is the same as that of the second treatment. A control group (CK) is set, the lawn is bare and uncovered, and there is no electric heating wire in the planting soil. Each treatment was repeated three times, and each test plot was divided by a red brick road with a depth of $30 \mathrm{~cm}$ below the ground. The testing

\footnotetext{
*Corresponding author: liumin@t5y.cn
} 
arrangement is shown in Figure 1.

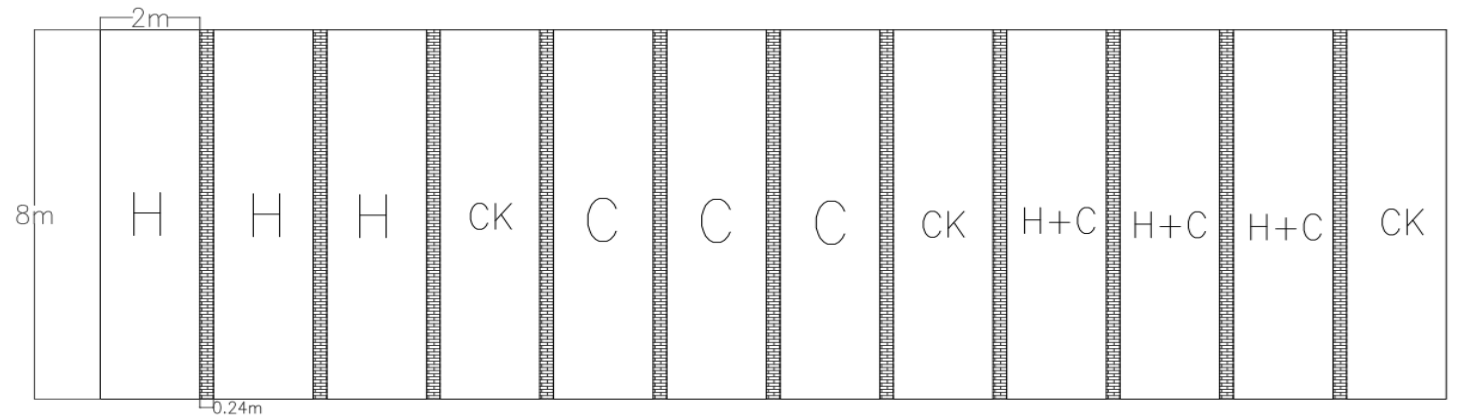

Figure 1 The testing arrangement

\subsection{Research Methods}

Observation indexes include air temperature, shallow soil temperature, and green lawn coverage (\%).

The temperature is measured by an alcohol thermometer, in which the air temperature data is recorded at 8:00, 14:00, and 18:00 per day, and the shallow soil temperature is recorded once a week at 8:00 a.m; green lawn coverage is the percentage of green lawn area in the area of the test plot. Based on the calculation of $100 \mathrm{~mm} \times 100 \mathrm{~mm}$ electronic coordinate grids combined with taking photos, the proportion of green areas exceeding half of the unit grid is counted as 1 , and the unit grid number is used to calculate the green coverage $[23,30]$.

\section{Results and Analysis}

\subsection{Effects of Treatments on shallow Soil Temperature of Lawn}

Compared with the control group, three treatments all increased the shallow soil temperature of the turf but the effect of temperature increase was different. Among them, group $\mathrm{C}$ increased $0-1^{\circ} \mathrm{C}$, but the effect was not significant $(\mathrm{P}>0.05)$. The temperature of group $\mathrm{H}$ increased by $3-5^{\circ} \mathrm{C}$, and the temperature of group $\mathrm{H}+\mathrm{C}$ increased by $5-8^{\circ} \mathrm{C}$. Group $\mathrm{H}$ and $\mathrm{H}+\mathrm{C}$ increased the shallow soil temperature of the lawn significantly $(\mathrm{P}<$ $0.01)$. The range of temperature rise of different treatments is shown in Figure 2, and the significance analysis results are shown in Table 1.

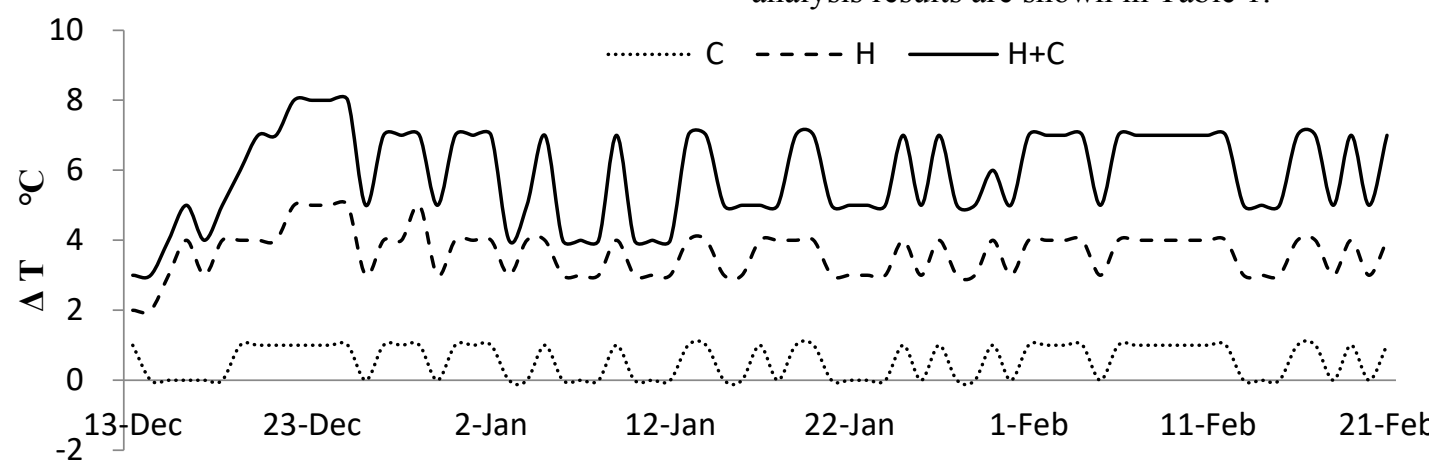

Figure 2 The range of temperature rise of different treatments

Table 1 The LSD result of temperature rise of different treatments

\begin{tabular}{ccccc}
\hline & & & Statistical \\
$(\mathrm{I})$ Processing & $(\mathrm{J})$ Processing & Mean Deviation (I-J) & Standard Deviation & Significance \\
\hline CK & C & -.54930 & .46440 & .238 \\
& H & $-3.63380^{*}$ & .46440 & .000 \\
& $\mathrm{H}+\mathrm{C}$ & $-5.88732^{*}$ & .46440 & .000
\end{tabular}

Covering non-woven fabrics has no significant effect on warming the shallow soil of the lawn $(-5 \mathrm{~cm}$ below surface) $(\mathrm{P}=0.238>0.05)$. Its main function is to prevent heat emission, which is related to the thickness of the material ${ }^{[28]}$, the fixing method and the method of removing the film ${ }^{[15]}$. In Fig. 2, it takes about 7 days for the temperature increasing effect to reach stability when the heat treatment is used, and there is a correlation with the meteorological conditions such as wind and basic air temperature. 


\subsection{Effect of Treatment on Green Lawn Coverage}

Through the observation of the green coverage of the test

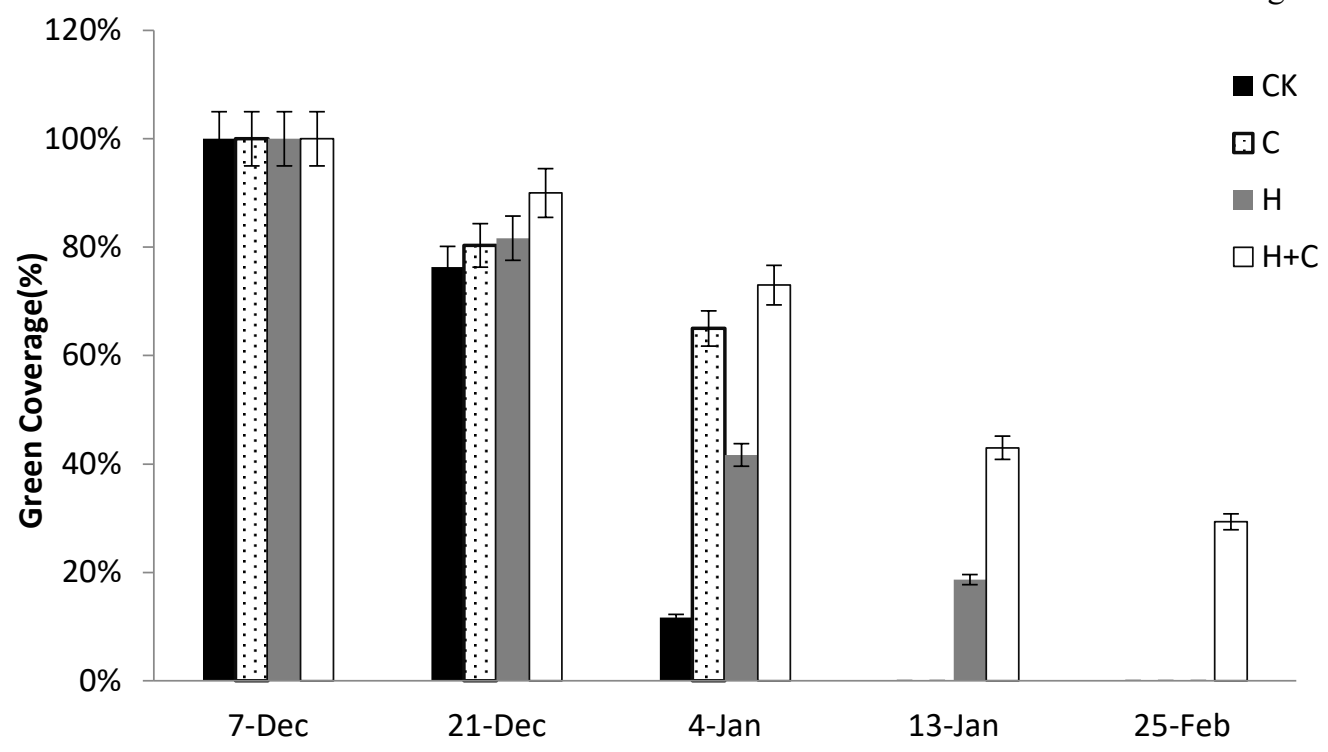

Figure 3 The green coverage of different treatments lawn, it was found that the green coverage of the lawn under different treatments had a great difference over time. The observations are shown in Figure 3.
Figure 3 shows that each treatment within two weeks of lawn laying has little effect on the green coverage of the lawn. The first reason is that the nutritional level of the lawn is basically the same when it comes out of the nursery. The second reason is that the temperature during the initial period of laying is relatively high (average $4.73^{\circ} \mathrm{C}$ ), which meets the survival needs of the lawn grass. In addition, the effects of increasing the temperature of each treatment are not obvious.

By mid-January, the green coverage of the control group significantly decreased compared to the treatment group until it reached 0 . It may be related to the lower average temperature $\left(-3.5^{\circ} \mathrm{C}\right)$ in January. The green coverage of the treatment group $\mathrm{C}$ maintained more than $70 \%$ within one month of laying, and then it quickly lost green, which may be related to the nutritional level of the lawn ${ }^{[27]}$. The green coverage of the $\mathrm{H}$ treatment group gradually decreased until it disappeared, which should be related to the gradual appearance of the heating effect of heating treatment.

In February, only the $\mathrm{H}+\mathrm{C}$ group maintained green coverage of about $30 \%$, and the other treatment groups completely lost green. It may be related to the invasion of the cold wave in the middle and late January. The daily maximum temperature during the cold wave is only $-12^{\circ} \mathrm{C}$. The effect of temperature increase cannot offset the continuous decline in temperature.

\subsection{Effect of Treatment on Green Lawn Period}

According to experimental statistics, different treatments have different effects on prolonging the lawn green period than the control group. Among them, the $\mathrm{H}+\mathrm{C}$ treatment had the best green extension effect. The turf in this group did not completely lose green during the test period, which was 53 days longer than the green period in the control group. Groups $\mathrm{C}$ and $\mathrm{H}$ were completely withered in mid-January, which were 10 to 12 days longer than the green period of the control group.

\section{Discussion and Prospect}

The lawn green period usually refers to the number of days from the day when $80 \%$ of the plants in the lawn plot turn green to the day when the plants turn yellow ${ }^{\text {[24]. }}$ There have been a lot of researches on methods to extend the green period of lawn, but most of them focus on how to extend the green period of warm-type lawn, and there is a lack of research on extending the cold-period lawn [11].

Wang Y.J. et al. summarized and analyzed the methods of extending the green period of the northern lawn [7], including: water and fertilizer management, heating, covering, growth regulators, new material concrete bricks, and spraying greening agents. The effects of fertilizer form, type, application time, and application amount on the extension of the green period of the lawn are quite different, and the application of nitrogen fertilizer has a positive effect on the extension of the green period of the lawn ${ }^{[12-14]}$. In this experiment, there was no significant difference in green coverage between the initial treatment group and the control group. The green coverage of the control group decreased rapidly in the later period, which proved the positive effect of nutrients on the green phase of the lawn.

Temperature affects plant transpiration, water potential, absorption and metabolism, as well as almost all enzymatic reactions, dormancy, growth and development ${ }^{[8]}$. When the air temperature is lower than the lowest limit of the turf-grass suitable growth, the turf-grass will gradually wither and enter a dormant period. Drought and low temperature in winter will reduce the overwintering rate of turf-grass ${ }^{[9]}$, in severe 
cases, it can also cause the death of turf-grass ${ }^{[10]}$. The SubAir system is a turf underground heating system that is widely used in Europe and the United States. In China, it is only in the initial stage of introduction. ${ }^{[16]}$. A more economical method is adopted in China, and the research shows that the plastic film covering can effectively improve the minimum temperature of the soil. In winter, lawns covered with plastic film and non-woven fabrics were regreened 30 days in advance ${ }^{[17]}$. Some scholars also treated the lawn of northern sports ground with heating and heat preservation, and the effect of warming and green preservation was significant $(\mathrm{P}<0.01)$, and there was no adverse effect on the growth of turf-grass in the future season ${ }^{[15]}$, which were consistent with the results of this experiment.

Studies have shown that foliar application of certain concentrations of $\mathrm{ABA}$ and other growth regulators can effectively increase the activity of the protective enzyme system of tall fescue, enhance cold resistance, and increase turf greenness ${ }^{[18]}$. The concrete brick is made of porous light volcanic rock, lava rock, aggregate, etc. with cement and additives, and there is enough pores in between, which is rich in nutrients required for grass species growth. Compared with ordinary lawns, the greening cycle can be extended by more than 1 month. Lawn greening agent is an environmental friendly biological staining agent, which can effectively fix to the lawn or soil, making the lawn natural green, maintaining green $60 \sim 120 \mathrm{~d}^{[7]}$. In addition to the above methods, strengthening the introduction and selection of turf-grass seeds ${ }^{[29]}$, determining reasonable sowing time and sowing ratio, and timely controlling diseases ${ }^{[26]}$ and insect pests are also important methods to extend the turf-grass green period ${ }^{[19-22,25]}$.

Some scholars' research on northern sports lawns found that once a week $(8-20 \mathrm{~h})$ is best to keep the film warm, however, once a day to remove the film is not good for temperature accumulation ${ }^{[15]}$. Covering measures can not only prevent heat from being released to heat preservation, but also can effectively reduce the loss of soil moisture ${ }^{[17]}$, and prevent drought stress on the lawn. The method of peeling the film, fixing the film and the material of the film have no obvious effect on the accumulation of soil temperature.

\section{Conclusion}

The turf in the north of China generally lost green in mid-November, and re-green in the following March or April. The annual green period was about 230 days ${ }^{[7]}$. This study was carried out in December to the following February. The $\mathrm{H}+\mathrm{C}$ treatment group did not completely lose green during the test period, indicating that after effective treatments were taken, the lawn in northern region of China can also achieve evergreen in a whole year. However, this experiment only conducted preliminary in the aspect of engineering temperature increase, and the conclusions reached were phased. The maintenance of the green period of the lawn is also related to many factors such as turfgrass variety, research area, pest control, and maintenance funds.

\section{Acknowledgments}

We wishing to acknowledge assistance from colleagues in field.

\section{Reference}

1. Zhao, D.J. (2009) Green design of road traffic. Commun Sci Technol Heilongjiang, 32(8):18.

2. Zhang, Z.H. (1995) Lawn and lawn playground. Pratacultural Science, 12(1): 66-68.

3. Jiang, Q., Sun, J.X. (2009) Function and design application of lawn landscape in garden. Bulletin of Agricultural Science and Technology, 10:71-74.

4. Sun, Y.Q., Dai, J.M. (1998) General situation and thinking of lawn industry development. Chinese Landscape Architecture, 14(56): 36-38.

5. Shan, H.J., Li, M.L. (2013) Recent development of turf grass industry in China. Acta Agrestia sinica, 21(2): 222-229.

6. Zhang, L.H. (2005) A preliminary study on the technology of turfgrass evergreen. Hunan Forestry Science\&Technology, 32(1):56-57.

7. Wang, J.Y., Xu, X.Z. (2015) Comparison of methods for prolong green period of northern turf grass.Modern Agricultural Science and Technology, 9:167-168.

8. You, M.H., Mao, K. (2003)Turf grass and temperature.Grassland and Turf, 1:15-18.

9. Strandberg, M. (2007) Winter injury on golf courses in Scandinavia. Swedish Golf Federation, Sweden.

10. Chang, Z.H. (2008) The coverage on northern green. China Flower \& Gardening Newspaper, 8.

11. Song, X.F. (2010) Effects of Different Mulching Methods on Soil Moisture,Soil Temperature and Turf Green Period in winter. Beijing Forestry University, Beijing.

12. Zhang, J.L, Guo, F.F. (2014) Effects of nitrogen on the quality and physiological characteristics of landscape turf. Shanxi Agricultural Economy, 4:78-80.

13. Tang, Y.F, Zuo, C.X. Gao G.X. (2007) Habits and Cultivation Techniques of Tall Fescue and Poa pratensis. Agricultural Technology Service, 24(4): 97.

14. Huang, L.L. (2005) Effect of Irrigation and Fertilization on the Green Period Prolonging of Cold-season Turfgrass in Lanzhou and its Mechanisms. Gansu Agricultural University , Lanzhou.

15. Bi, Y.F. (2001) Warming Turfground to Prolong the Growing Season for Sports Turf in Winter in Northern China. Grassland and Turf, 2:22-26.

16. Hou, G.H, Chen, Q.J. (2013) Application prospect of SubAir System in golf courses in China. Grassland and Turf, 33(5): 105-110.

17. Song, X.F, Su, D.R. (2010) Effect of Plastic Film 
Mulching on Prolonging Turf Green Period in Winter. ACTA AGRECTIR SINICA, 18(3): 441-446.

18. Liu, L.J, Chen, W.F. (2010) Effects of Foliar Spraying ABA on Cold Resistance of Festuca arundinacea. Chinese Journal of Grassland, 32(6):94-99.

19. He, Y.L. (2009) Study on the application of overseeding to Zoysia japonica turf in Beijing Region. Beijing Forestry University, Beijing.

20. He, J.Y., Zhou, J.J. (2016) Effect of different seeding rate combinations on turf quality between kentucky bluegrass and tall fescue. Grassland and Turf, 36(2): 92-96.

21. Meng, F.Y. (2004) Study on the cold-season turfgrass ecological adaptation and cold tolerance. Northeast Normal University, Changchun.

22. Li, X.G., Zhang, Z.H. (2005) Study on adaptability and performance evaluation of thirty turfgrasses introduced to Beijing area. Pratacultural Science, 22(6): 96-100

23. Ji, Y.X., Zhang, L.M. (2007) Study on related parameters for turf color evaluation using digital photography. Pratacultural Science, 24(5): 94-98.

24. Sun, J.X., Han,L.B. (2015) Turf Science. China Agriculture Press, Beijing.

25. Wang, Y.F. (2013) Primary Exploration for Expressway Green Conservation. Northern Communications, 5: 45-46.

26. Williams, D.W., Burrus, P.B. (2001) Severity of gray leaf spot in perennial ryegrass as influenced by mowing height and nitrogen level. Crop Science, 41:1207-1211.

27. Glibert, W.B., Davis, D.L. (1971) Influence of fertilizer ratios on winter hardiness of bermudagrass. Agronomy journal, 63: 591-593.

28. Crossi, N., Volterrani, M. (2006) Cover materials for winter protection of turf. Colture protette, 35(4):.146-149.

29. Dionne, J., Rochefort, S. (2010) Variability for freezing tolerance among 42 ecotypes of green-type annual Bluegrass. Crop Science, (50): 321-336.

30. Karcher, D.E., Richardson M.D. (2003) Quantifying turfgrass color using digital image analysis. Crop Science, 43: 943-951. 